\title{
Volatile organic compound emissions from the oil and natural gas industry in the Uintah Basin, Utah: oil and gas well pad emissions compared to ambient air composition
}

\author{
C. Warneke ${ }^{1,2}$, F. Geiger ${ }^{3}$, P. M. Edwards ${ }^{1,2}$, W. Dube ${ }^{1,2}$, G. Pétron ${ }^{1,4}$, J. Kofler $^{1,4}$, A. Zahn ${ }^{3}$, S. S. Brown ${ }^{2}$, \\ M. Graus ${ }^{1,2}$, J. B. Gilman ${ }^{1,2}$, B. M. Lerner ${ }^{1,2}$, J. Peischl ${ }^{1,2}$, T. B. Ryerson ${ }^{2}$, J. A. de Gouw ${ }^{1,2}$, and J. M. Roberts ${ }^{2}$ \\ ${ }^{1}$ Cooperative Institute for Research in Environmental Sciences, Univ. of Colorado, Boulder, CO, USA \\ ${ }^{2}$ NOAA Earth System Research Laboratory, Chemical Sciences Division, Boulder, CO, USA \\ ${ }^{3}$ Karlsruhe Institute of Technology, IMK-ASF, Karlsruhe, Germany \\ ${ }^{4}$ NOAA Earth System Research Laboratory, Global Monitoring Division, Boulder, CO, USA
}

Correspondence to: C. Warneke (carsten.warneke@noaa.gov)

Received: 8 April 2014 - Published in Atmos. Chem. Phys. Discuss.: 13 May 2014

Revised: 21 August 2014 - Accepted: 6 September 2014 - Published: 17 October 2014

\begin{abstract}
Emissions of volatile organic compounds (VOCs) associated with oil and natural gas production in the Uintah Basin, Utah were measured at a ground site in Horse Pool and from a NOAA mobile laboratory with PTR-MS instruments. The VOC compositions in the vicinity of individual gas and oil wells and other point sources such as evaporation ponds, compressor stations and injection wells are compared to the measurements at Horse Pool. High mixing ratios of aromatics, alkanes, cycloalkanes and methanol were observed for extended periods of time and for short-term spikes caused by local point sources. The mixing ratios during the time the mobile laboratory spent on the well pads were averaged. High mixing ratios were found close to all point sources, but gas well pads with collection and dehydration on the well pad were clearly associated with higher mixing ratios than other wells. The comparison of the VOC composition of the emissions from the oil and natural gas well pads showed that gas well pads without dehydration on the well pad compared well with the majority of the data at Horse Pool, and that oil well pads compared well with the rest of the ground site data. Oil well pads on average emit heavier compounds than gas well pads. The mobile laboratory measurements confirm the results from an emissions inventory: the main VOC source categories from individual point sources are dehydrators, oil and condensate tank flashing and pneumatic devices and pumps. Raw natural gas is emitted from the pneumatic devices and pumps and heavier VOC mixes from the tank flashings.
\end{abstract}

\section{Introduction}

Since the introduction of hydraulic fracturing and horizontal drilling, the extraction of shale gas, often called unconventional natural gas, has increased and comprised $40 \%$ of total production of natural dry gas in 2012 in the United States (US Energy Information Administration, 2014). In the Uintah Basin in Utah, the production of oil and natural gas also has increased in recent years and currently about 8000 gas wells and 2000 oil wells are in operation, with about 1000 wells added each year (Utah Oil and Gas, 2014). Most of the oil wells are located in Duchesne County on the western side of the basin, and the gas wells are in Uintah County on the eastern side. In addition, there are also about 1000 coal bed methane wells and conventional wells located in Carbon County south of Uintah County. This intense oil and natural gas extraction operation results in emissions of greenhouse gases (mostly methane), volatile organic compounds (VOCs) and nitrogen oxides $\left(\mathrm{NO}_{\mathrm{x}}\right)$ (Gilman et al., 2013; Howarth et al., 2011; Karion et al., 2013; Katzenstein et al., 2003; Kemball-Cook et al., 2010; Litovitz et al., 2013; Petron et al., 2012; Swarthout et al., 2013). Some of the VOCs emitted by oil and gas extraction are air toxins and can have direct health impacts for oil and gas workers and local residents (McKenzie et al., 2012). VOCs and $\mathrm{NO}_{\mathrm{x}}$ can produce ozone in the atmosphere, which is generally seen as a summertime issue. In the Uintah Basin, however, ozone formation leading to mixing ratios above the EPA National Ambient Air 
Quality Standard (NAAQS) has been frequently observed in the winter, when the ground was snow covered and strong temperature inversions persisted for several days (Schnell et al., 2009). The identification of the emission sources of VOCs and $\mathrm{NO}_{\mathrm{x}}$ from oil and natural gas production in the Uintah Basin is key to understanding the processes leading to the formation of wintertime ozone.

While there were no ozone exceedances in the Uintah Basin in 2012 due to weaker temperature inversions and the absence of snow (Edwards et al., 2013), these conditions were very amenable to study VOC emissions. Here we present measurements of VOCs using Proton Transfer Reaction Mass Spectrometry (PTR-MS) from UBWOS2012 (Uintah Basin Winter Ozone Study 2012) in the Uintah Basin in February 2012 at a ground site in Horse Pool and onboard a mobile laboratory in order to characterize the VOC composition of the emissions from individual gas and oil well pads and other point sources such as evaporation ponds, compressor stations and injection wells. Recent studies using mobile platforms have focused on methane emissions from oil and gas activities in the Uintah Basin and elsewhere (Allen et al., 2013; Karion et al., 2013). In this publication we focus primarily on VOCs.

\section{Experimental}

\subsection{Instrumentation}

The UBWOS2012 study included a ground site in Horse Pool, Utah and the National Oceanic and Atmospheric Administration Global Monitoring Division (NOAA GMD) mobile laboratory. The Horse Pool ground site was fully equipped with a large suite of gas phase and aerosol measurements and only the instruments used in this study are described here. VOC measurements were made using PTRMS instruments: the NOAA PTR-MS, which is described in detail by de Gouw and Warneke (de Gouw and Warneke, 2007) and the newly developed Karlsruhe Institute of Technology (KIT) ULW-PTR-MS (ultra-light weight PTR-MS). PTR-MS is an online mass spectrometric technique for measuring VOCs in the atmosphere. In PTR-MS, $\mathrm{H}_{3} \mathrm{O}^{+}$ions are used to ionize the compounds of interest in a reaction chamber and the primary and product ions are detected by a quadrupole mass spectrometer (de Gouw and Warneke, 2007). The NOAA PTR-MS was deployed at the Horse Pool ground site for the duration of the study from 15 January to 29 February 2012, while the KIT PTR-MS was used at the ground site for the first 3 weeks for detailed comparisons, and onboard the mobile laboratory for the next 3 weeks. The two PTR-MS instruments had similar reaction chambers and mass spectrometers, but the KIT ULW-PTR-MS was optimized for instrument size and weight and was $130 \mathrm{lbs}$ (ca. $59 \mathrm{~kg}$ ) compared to the standard PTR-MS, which is about $250 \mathrm{lbs}$ (ca. $113 \mathrm{~kg}$ ). At the time of the study, the KIT ULW-
PTRMS had a somewhat lower sensitivity of around 100$200 \mathrm{cps} \mathrm{ppbv}^{-1}$ compared to about $500-1000 \mathrm{cps} \mathrm{ppbv}^{-1}$ of the NOAA PTR-MS. After the study, the sensitivity of the KIT ULW-PTR-MS was improved by about a factor of 3 . Calibrations were performed at the Horse Pool ground site every other day using a calibration standard with 10 different VOCs, including oxygenates, aromatics and other compounds, and the mobile organic carbon calibration system (MOCCS) (Veres et al., 2010) for formaldehyde. The measurements at the ground site are averaged to $1 \mathrm{~min}$ data and the individual compounds on the mobile laboratory were measured for $0.5 \mathrm{~s}$ every $19 \mathrm{~s}$. At the ground site the two instruments used the same inlet, the same calibration set-up and were located in the same trailer. The two instruments agreed for all reported VOCs within $10 \%$ (not shown here), which gives a good confidence for the comparison of the ground site data with the mobile laboratory data.

VOCs were also measured at Horse Pool using an online gas chromatograph-mass spectrometer (GC-MS). The GCMS sampled air for $5 \mathrm{~min}$ every $30 \mathrm{~min}$ and measured, among others, speciated $\mathrm{C}_{2}-\mathrm{C}_{12}$ alkanes, $\mathrm{C}_{5}-\mathrm{C}_{8}$ cycloalkanes, $\mathrm{C}_{6}-$ $\mathrm{C}_{9}$ aromatics and methanol. The instrument is described in more detail elsewhere (Gilman et al., 2010, 2013).

Methane was measured at Horse Pool using a 3-channel Picarro for $\mathrm{CO}_{2}, \mathrm{CH}_{4}$ and water vapor (Peischl et al., 2012) and on the NOAA GMD mobile laboratory using a 4-channel Picarro for $\mathrm{CO}_{2}, \mathrm{CO}, \mathrm{CH}_{4}$ and water vapor.

A two-channel cavity ring-down spectrometer instrument NOxCaRD (Nitrogen Oxide Cavity Ring Down) was deployed in the mobile laboratory for the direct measurement of $\mathrm{NO}_{2}$ by optical extinction at $405 \mathrm{~nm}$, as described in Fuchs et al. (2009), and of either $\mathrm{NO}_{\mathrm{x}}\left(=\mathrm{NO}_{2}+\mathrm{NO}\right)$ or $\mathrm{O}_{\mathrm{x}}(=$ $\mathrm{NO}_{2}+\mathrm{O}_{3}$ ) after chemical conversion to $\mathrm{NO}_{2}$. Simultaneous $\mathrm{NO}_{2}$ and $\mathrm{NO}_{\mathrm{x}}$ or $\mathrm{O}_{\mathrm{x}}$ observations were made at a measurement frequency of $1 \mathrm{~Hz}$. Calibrations, based on the absorption cross section of $\mathrm{NO}_{2}$, were performed periodically and used a commercial $\mathrm{O}_{3}$ monitor to generate and measure a known $\mathrm{O}_{3}$ concentration, which was then quantitatively converted to $\mathrm{NO}_{2}$. During the mobile laboratory drives, the NOxCaRDs precision was approximately 50 pptv $(2 \sigma, 1 \mathrm{~s})$, and the accuracy, based on the consistency of the in-field calibrations, was $\pm 3 \%$ for $\mathrm{NO}_{2}$ and $\pm 8 \%$ for either $\mathrm{NO}_{\mathrm{x}}$ or $\mathrm{O}_{\mathrm{x}}$.

\subsection{PTR-MS VOC identification and inter-comparison}

PTR-MS uses $\mathrm{H}_{3} \mathrm{O}^{+}$ions to ionize VOCs of interest, which react fast with all compounds that have a higher proton affinity than that of water (de Gouw and Warneke, 2007). Among the compounds of interest for oil and gas emissions, this includes the aromatic compounds and methanol. Straight chain, branched and cyclic alkanes generally have a lower proton affinity than water. Those compounds, together with methane, make up more than $90 \%$ of the mass of crude oil and natural gas (Ryerson et al., 2011). 

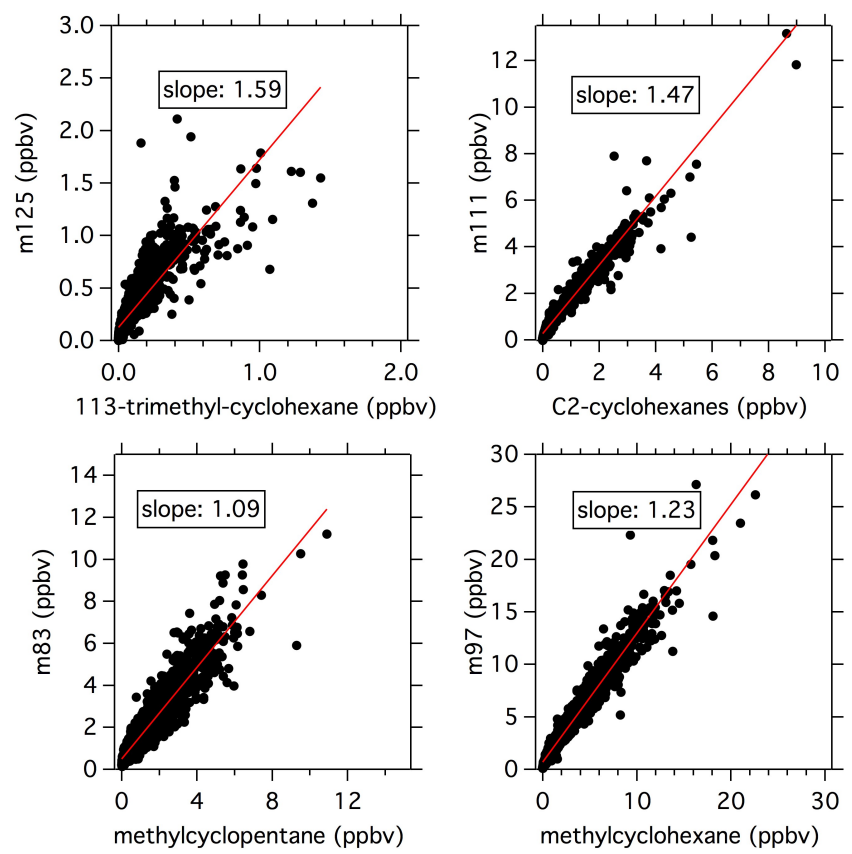

Figure 1. Inter-comparison of the masses measured by PTR-MS that are indicative of cycloalkanes with GC-MS cycloalkane mixing ratios at the Horse Pool site.

Even though cycloalkanes have a lower proton affinity than water, they react with $\mathrm{H}_{3} \mathrm{O}^{+}$, albeit at a slower rate of about $10 \%$ compared to most other VOCs. The most common pathway after reaction with $\mathrm{H}_{3} \mathrm{O}^{+}$is proton transfer accompanied by hydrogen abstraction, such that the main masses produced from cycloalkanes in PTR-MS are masses $69,83,97,111$, and 125. Alkenes are also detected at these masses, especially isoprene, which is detected at mass 69. At the Horse Pool site only small amounts of alkenes were detected using GC-MS compared to alkanes and cycloalkanes, and we therefore assume that the main contributors to those masses in the Uintah Basin are cycloalkanes. Using the fragmentation patterns determined by Yuan et al. (2014) we conclude that mass 83 is mainly from methylcyclopentane, mass 97 from methylcyclohexane, mass 111 and mass 69 from the C2-cyclohexanes, and mass 125 from the C3cyclohexanes. PTR-MS calibrations of methylcyclopentane, methylcyclohexane, and 1,2-dimethylcyclohexane were performed prior to and during the field study using the MOCCS system (Veres et al., 2010). Using the determined sensitivities and mass identifications, the cycloalkanes from the PTRMS are compared to the GC-MS at Horse Pool and the results are shown in Fig. 1. The two instruments agreed within the stated uncertainty of about $20 \%$ for both instruments, which gives some confidence for the use of the PTR-MS cycloalkane mass signals. The PTR-MS signals for all measured cycloalkanes are larger than the GC-MS, which might indicate small interferences from other compounds besides the ones used in the sum of the GC-MS signals in Fig. 1.
Here it should be mentioned that the cycloalkanes also react quickly with $\mathrm{O}_{2}^{+}$, which is about $1-5 \%$ of $\mathrm{H}_{3} \mathrm{O}^{+}$in the PTR-MS, but the contributions from $\mathrm{O}_{2}^{+}$reactions to the cycloalkane masses are likely small compared to $\mathrm{H}_{3} \mathrm{O}^{+}$(Yuan et al., 2014).

Small alkanes, on the other hand, do not react with $\mathrm{H}_{3} \mathrm{O}^{+}$, they only undergo charge transfer reactions with $\mathrm{O}_{2}^{+}$, which results in many different fragment ions with various masses (Francis et al., 2007; Spanel and Smith, 1998; Yuan et al., 2014). Small alkanes are therefore not detected very selectively and only with a very low sensitivity with PTR-MS. During UBWOS2012 we monitored several of those alkane masses and in the following we will use masses 43, 57, 71, and 85 . Each of these masses have contributions from several alkanes, straight-chain and branched, such that none of the masses can be used quantitatively for individual compounds, but generally the lighter the alkane is, the smaller the resulting ions are (Francis et al., 2007). Calibrations for several alkanes were performed in the lab and the determined sensitivities were about $3 \%$ of other VOCs, which was used to convert alkane mass signals into approximate corresponding mixing ratios. These masses are also common fragments of other compounds, such as alcohols and ketones (Warneke et al., 1996, 2003). Using the VOC composition at Horse Pool measured by GC-MS during UBWOS2012, the signals from these other compounds are expected to be small compared to the signals resulting from the alkanes. The alkane masses will be used in this work only as indicators for the presence of small alkanes.

\section{Results and discussion}

\subsection{Mixing ratios at the ground site in the Uintah Basin}

A map of the Uintah Basin that indicates the locations of the oil and gas wells and several other point sources is shown in Fig. 2. The Horse Pool ground site and the drive tracks used for this study with the mobile laboratory are shown as well. The Horse Pool ground site is at the northern edge of the gas field and surrounded by many gas wells as well as a few oil wells to the north of the site, as shown in the insert map in Fig. 2. The whole Uintah Basin has only a few minor towns (several tens of kilometers away from Horse Pool) and the Bonanza power plant, but its emissions were generally lofted from the stack outside the mixed layer. The top panel of Fig. 3 shows a time series for benzene and toluene for one selected day, and the other panels selected VOCs for the UBWOS2012 campaign. The mixing ratios observed at the site are characterized by high values for extended periods of time during stagnation events in the basin and by very high mixing ratios during short-term spikes (caused by local point sources such as the oil and gas wells shown in the inserted map in Fig. 2). For example, benzene and toluene were over 3 ppbv from 30 January to 2 February before the basin cleaned out 


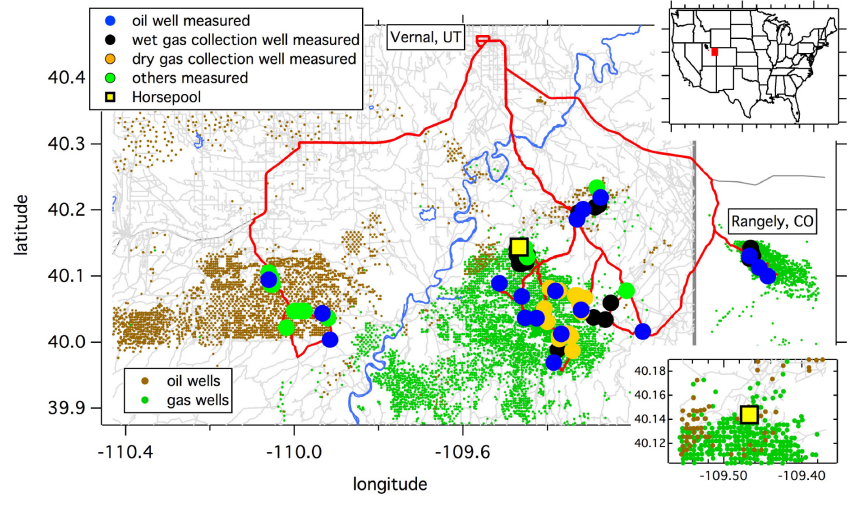

Figure 2. A map of the Uintah Basin study area showing the locations of oil and gas wells and the Horse Pool ground site. The route of the drives (red lines) is shown together with the locations of the investigated point sources. The insert on the top shows the location of the Uintah Basin in the United States and the bottom insert shows the immediate vicinity of the Horse Pool site, which is surrounded by oil and gas wells.

just after noon on 2 February. In addition, toluene spikes of well over $10 \mathrm{ppbv}$ for $1 \mathrm{~min}$ average data were frequently observed. Methanol, used as an anti-freeze and anti-coagulant in gas and oil wells, was almost an order of magnitude higher than the aromatics, and mixing ratios of several hundreds of ppbv were detected in the spikes. The smallest mixing ratios were observed after a clean-out event on 2 February 2012 and mixing ratios dropped to typical wintertime continental background levels.

\subsection{Typical mixing ratios downwind of point sources}

To investigate the emissions from point sources in the Uintah Basin that are responsible for the elevated mixing ratios of VOCs observed at the Horse Pool ground site, the mobile laboratory was used to measure immediately downwind of individual facilities: (1) gas well pads with dehydration not on the well pad but consolidated at a central facility, (2) gas well pads with collection and dehydration on the well pad, (3) oil wells, (4) gas well pads near Rangely, Colorado, (5) a recently hydraulically re-fractured well with a flowback pond, (6) a newly producing gas well and (7) other point sources, including natural gas compressor stations, produced-water injection wells, condensate and oil tank batteries, evaporation ponds and water treatment plants.

A photograph of a typical gas well pad in the Uintah Basin is shown in Fig. 4a together with an oil well pad in Fig. 4c, and typical mixing ratios downwind of such wells are shown in Fig. 5 (gas well pad) and Fig. 6 (oil well pad). The track of the mobile laboratory in close proximity downwind (indicated by the wind barbs) of the well pads are shown in Figs. 5b-e and $6 \mathrm{~b}-\mathrm{e}$ and are color coded by methane, methanol, toluene, and $\mathrm{NO}_{2}$, respectively. The corresponding time series are shown in Figs. 5a and 6a. Close to this
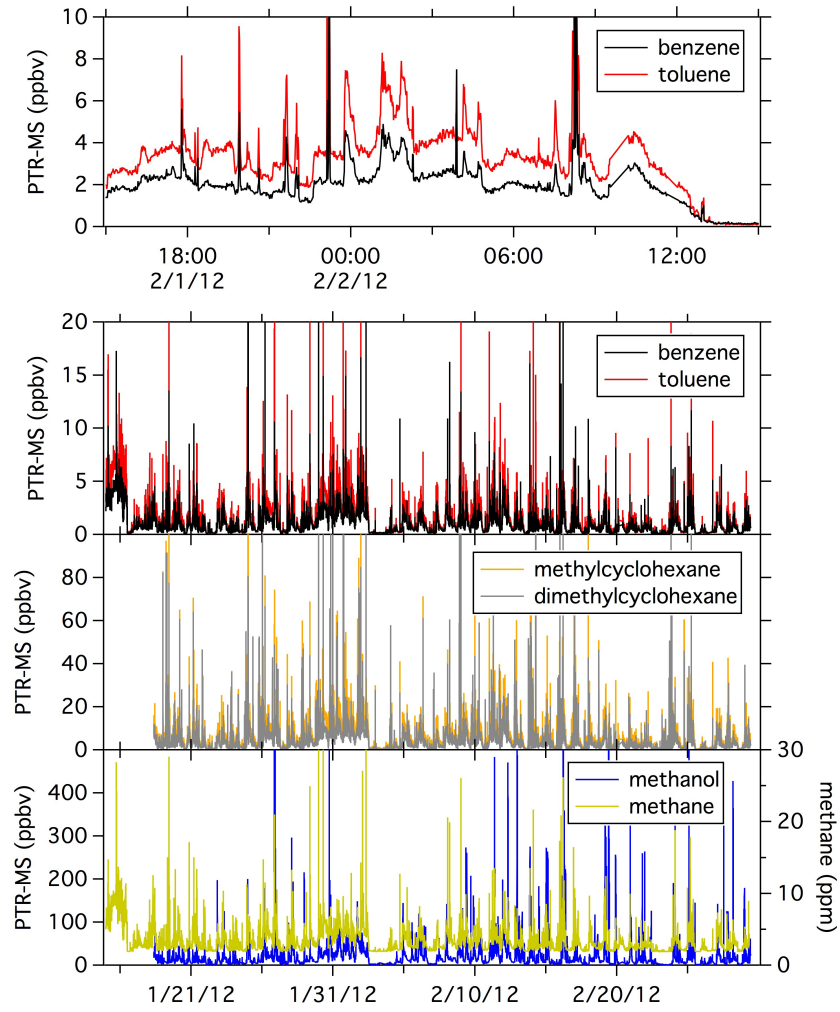

Figure 3. The time series of benzene and toluene for 1 day and various VOCs measured by PTR-MS and methane for the whole measurement period at the Horse Pool ground site during the UBWOS2012 campaign. Maximum mixing ratios are off-scale.

particular gas well pad, over $10 \mathrm{ppmv}$ of methane, $40 \mathrm{ppbv}$ of toluene and $500 \mathrm{ppbv}$ of methanol were detected (Fig. 5). These three compounds illustrate the elevated mixing ratios close to the well pad and also that different components of the gas well pad are responsible for different emissions. At most well pads, methane is highest downwind of the separator, but is also emitted from the wellhead. Toluene and other aromatics are highest downwind of the condensate and water tanks. Methanol is highest downwind of the methanol and condensate tanks, and $\mathrm{NO}_{2}$ downwind of the compressor. This means that the handling of the gas causes emissions of natural gas and the processing of the gas emissions of the heavier compounds, so-called fugitives. As a result, the heavier VOCs are not well correlated with methane on the well pads.

At many oil well pads, such as the one shown in Fig. 6, oil tanks were used, which were the main source for the aromatic compounds similar to the gas well condensate tanks. Methane comes from the wellhead, methanol from the wellhead and the pump jack, and the $\mathrm{NO}_{2}$ comes mainly from the generator and the pump jack, which is typically driven by an internal combustion engine (Fig. 6). At the Horse Pool ground site all of these compounds were much better correlated, because there was enough time for mixing after the 

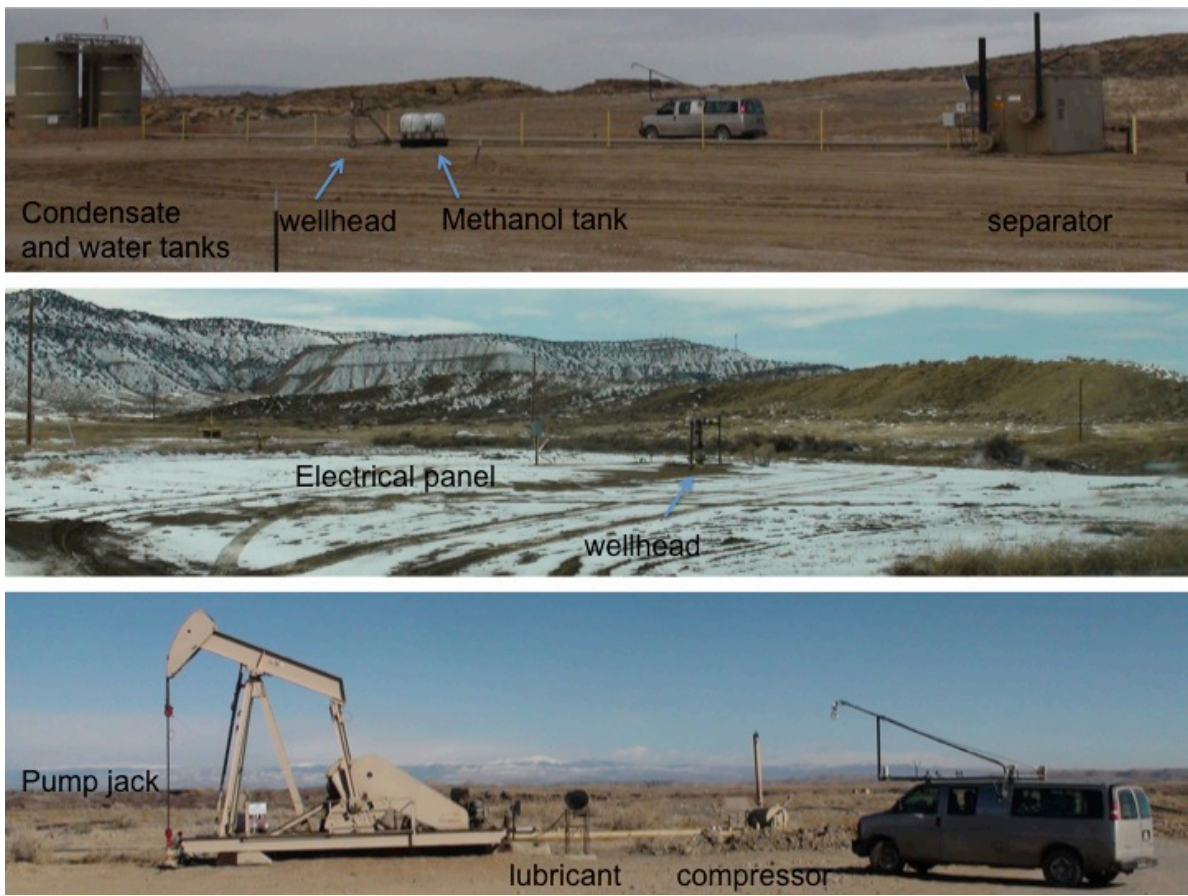

Figure 4. Top: picture of a typical natural gas well pad in the Uintah Basin. Middle: picture of a typical natural gas well in Rangely, Colorado. Bottom: picture of a typical oil well in the Uintah Basin.
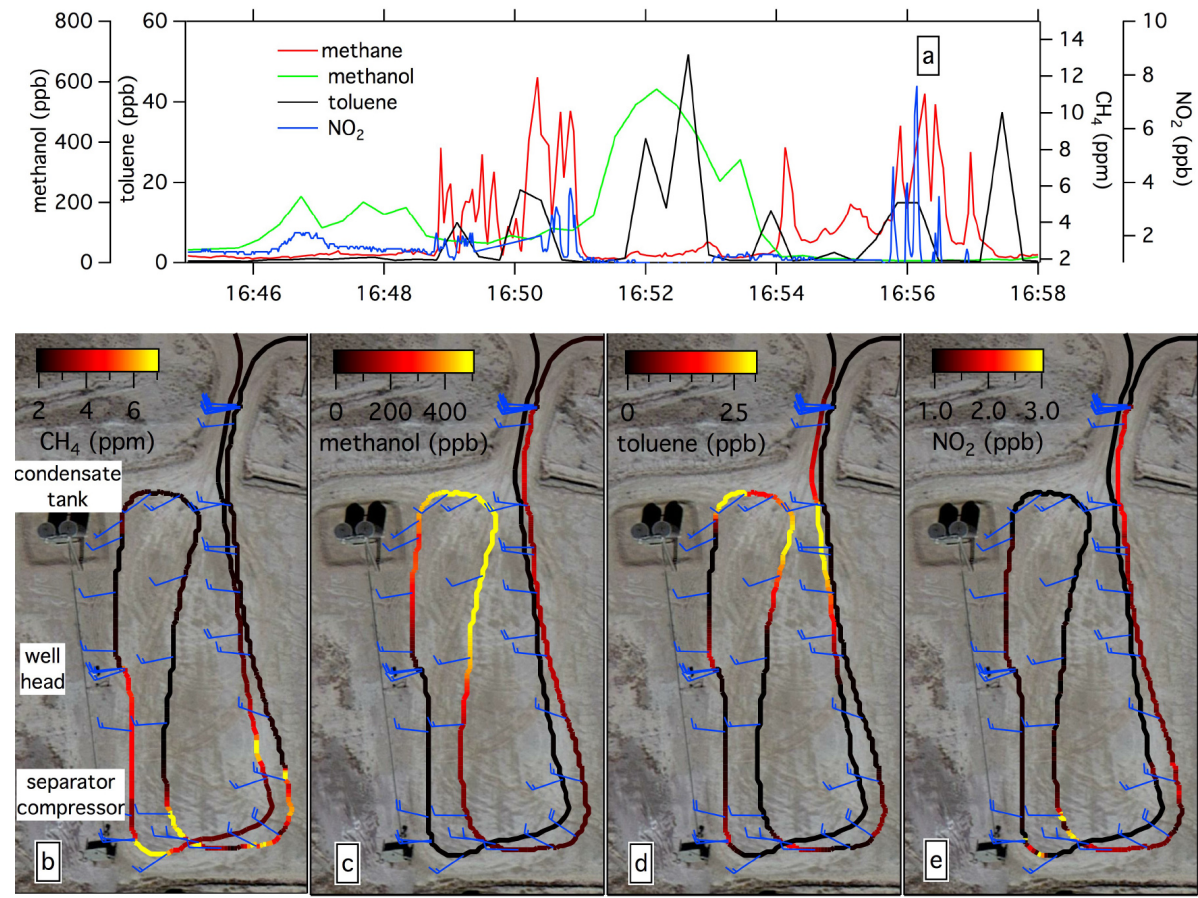

Figure 5. The drive track close to a gas well color coded by measured methane (b), methanol (c), toluene (d) and $\mathrm{NO}_{2}(\mathbf{e})$. The wind barbs indicate the prevailing wind direction coming from left to right in the image. The time series for this period is shown in (a).

emission. In Figs. 5 and 6 it can be seen that in a few occasions the plume was not measured on some of the transects, which is a result of the variable wind speed and direction and also of incomplete mixing so close to the emission source. 

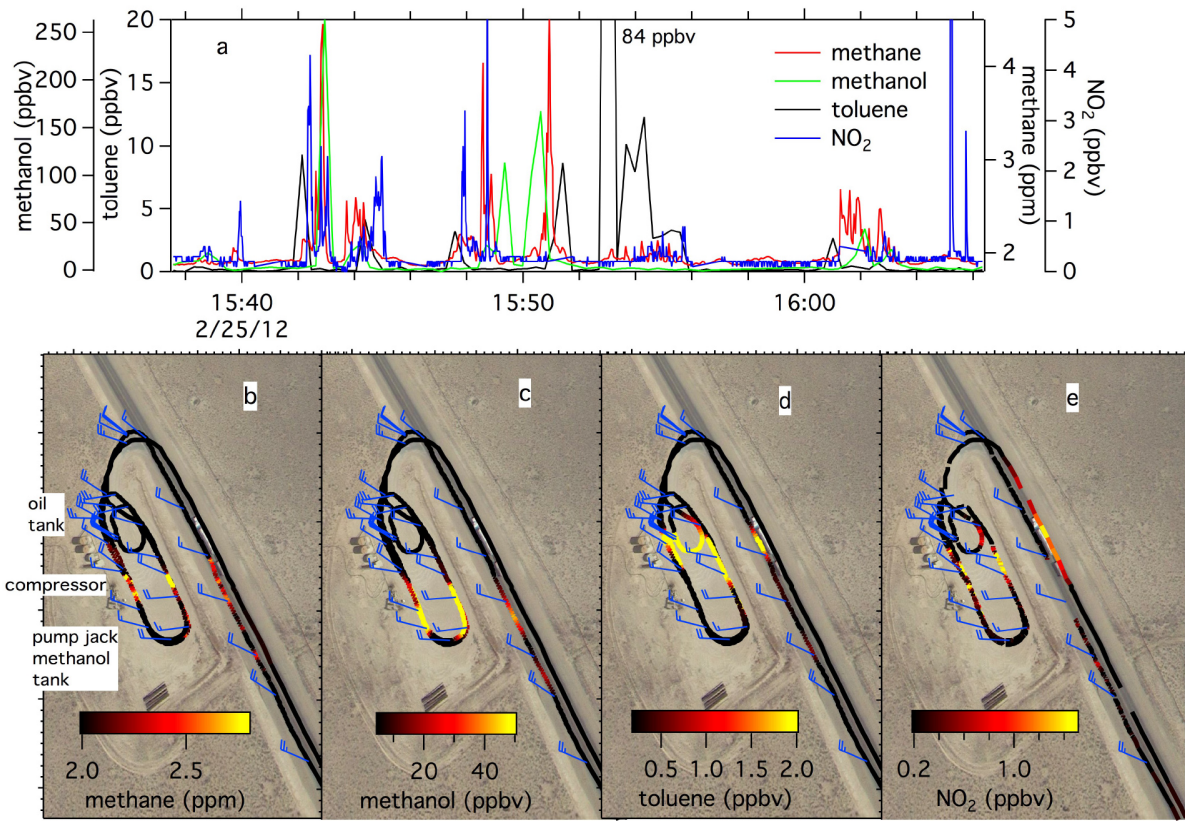

Figure 6. The drive track close to an oil well color coded with methane (b), methanol (c), toluene (d) and $\mathrm{NO}_{2}$ (e). The wind barbs indicate the prevailing wind direction. The time series for this period is shown in (a).

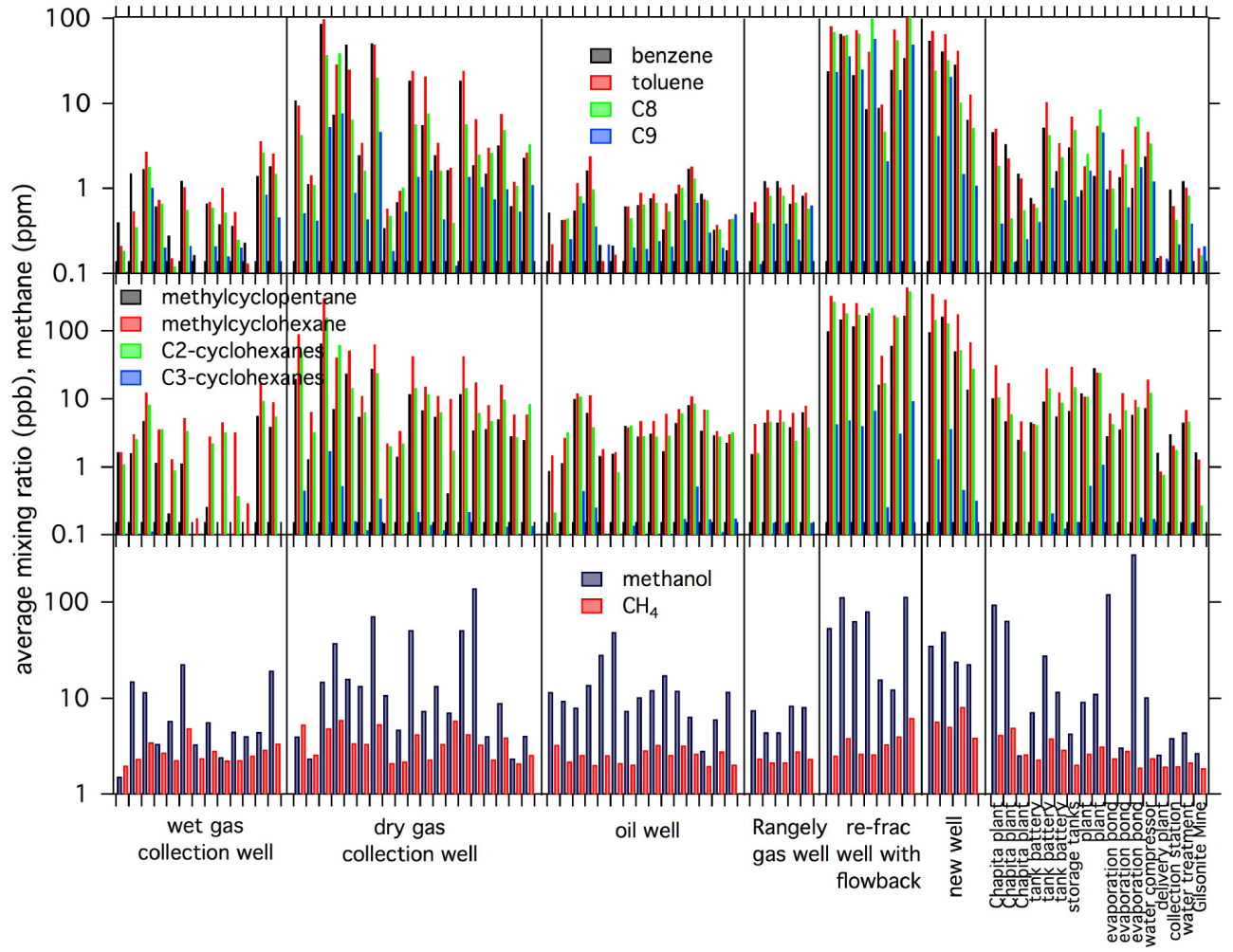

Figure 7. The average mixing ratios of various VOCs (aromatics, cycloalkanes, methanol and methane) observed close to individual point sources in the Uintah Basin and in Rangely, Colorado.

During UBWOS2012 38 different gas well pads, 12 oil well pads, a newly producing well, a re-fractured well with a flow back pond, and 17 other point sources such as evaporation ponds, storage tanks and compressor stations were 


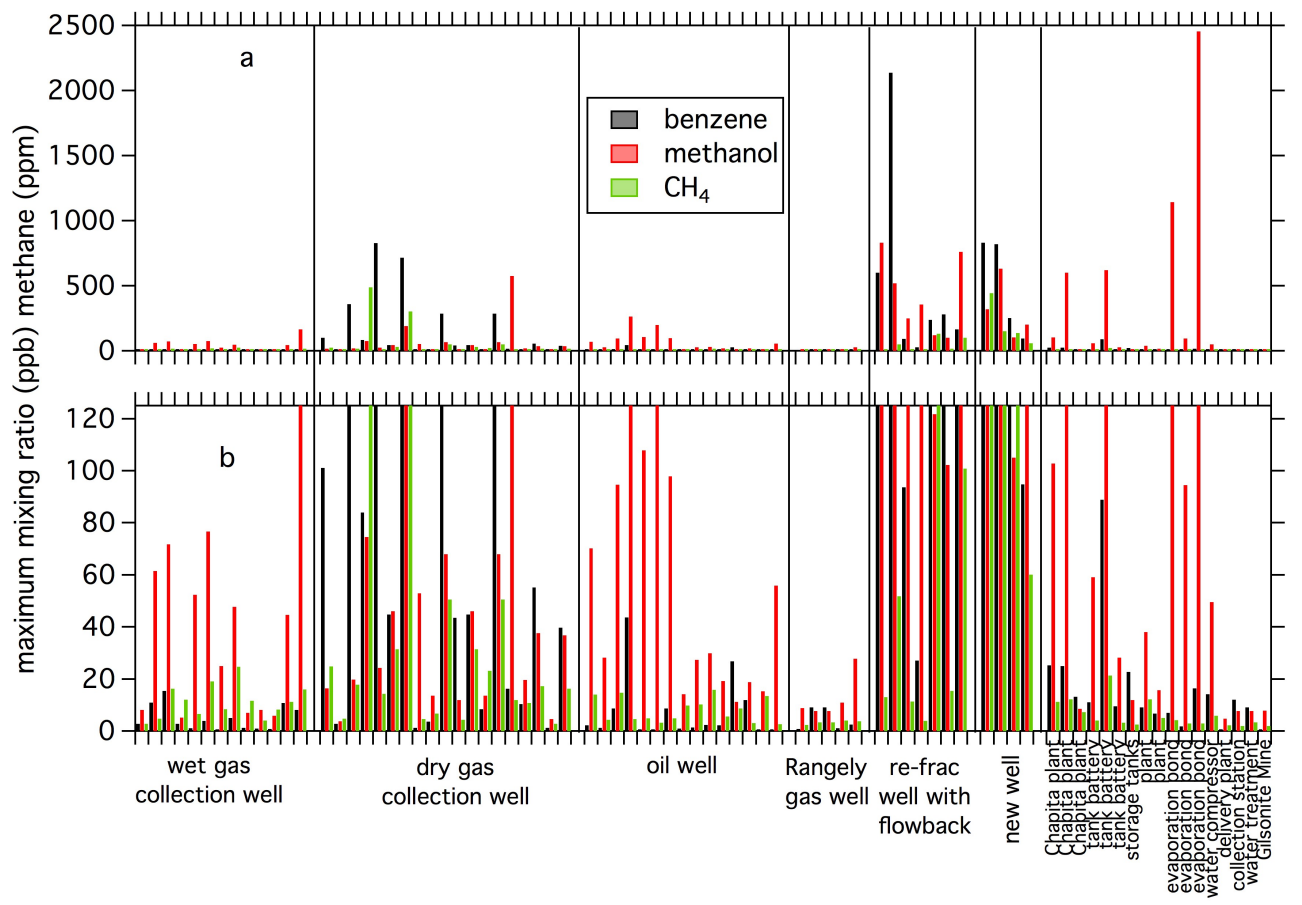

Figure 8. The maximum mixing ratio of benzene, methanol and methane observed close to the investigated emission sources in the Uintah Basin and in Rangely, Colorado. (a) Full scale and (b) small scale.

investigated in a similar way as described above. The mixing ratios of the measured VOCs were averaged during the time the mobile laboratory spent in close proximity downwind, generally within 300 feet of the wells or the other emission sources, in order to provide a means of comparison with the Horse Pool site measurements and aggregated emissions inventories. The results are shown in Fig. 7. This average is somewhat influenced by the relative amount of background air encountered during the averaging time, but this does not influence the conclusions in this work. It should also be mentioned here that the measurements on the well pads were taken during periods when no truck traffic was in the vicinity. The maximum observed mixing ratios close to the sources for selected VOCs and methane (shown in Fig. 8) show similar trends as the averages, but also give an indication of how elevated mixing ratios close to the sources were. Figures 5, 6, 7 and 8 demonstrate that mixing ratios of aromatics and methanol near $1 \mathrm{ppmv}$ and of methane of hundreds of ppmv were measured several times during the drives.

The data in Fig. 7 are then normalized to $2 \mathrm{~ms}^{-1}$ wind speed (dividing the mixing ratio by the wind speed in $\mathrm{m} \mathrm{s}^{-1}$ and multiplying by $2 \mathrm{~m} \mathrm{~s}^{-1}$ ) to account for different dilutions at different wind speeds by using the average observed horizontal winds over the same time period. The wind-speednormalized results for only the gas and oil well pads are averaged and shown in Fig. 9. Here it should be mentioned that we do not have any information about the vertical extent of the plumes from the gas wells and the other point sources, such that an estimate of emission rates is not possible; therefore, only average mixing ratios close to the sources are discussed here.

Strongly elevated mixing ratios of the measured VOCs were found at almost all source locations, but very large differences existed - even between similar point sources. The largest relative differences were observed between individual gas well pads. For example, average normalized toluene mixing ratios $<10 \mathrm{ppbv}$ were observed next to several gas wells, but in the same gas field or formation 2 orders of magnitude larger mixing ratios of $>100 \mathrm{ppbv}$ were found next to other gas wells. The average mixing ratios close to investigated oil well pads in Duchesne County (Fig. 9) generally show smaller mixing ratios than gas wells using dehydrators as well as similar gas wells without dehydrators in Uintah County. The mobile laboratory usually spent about 20-30 min close to each gas well pad and generally no variations on the order of the well-to-well variability were observed. This seems to indicate that the main reason for the different emissions is the different practices and, as a result, different equipment used for wells that have the dehydration on the well pad compared to wells with only the gas collection, where the dehydration is consolidated at a central facility. On the well pads with dehydration, glycol dehydrators that include a heater and a glycol regenerator are used. All of these components have VOC emissions and therefore this category has higher mixing ratios associated with them. Wells with only the gas collection on the well pad do not use 


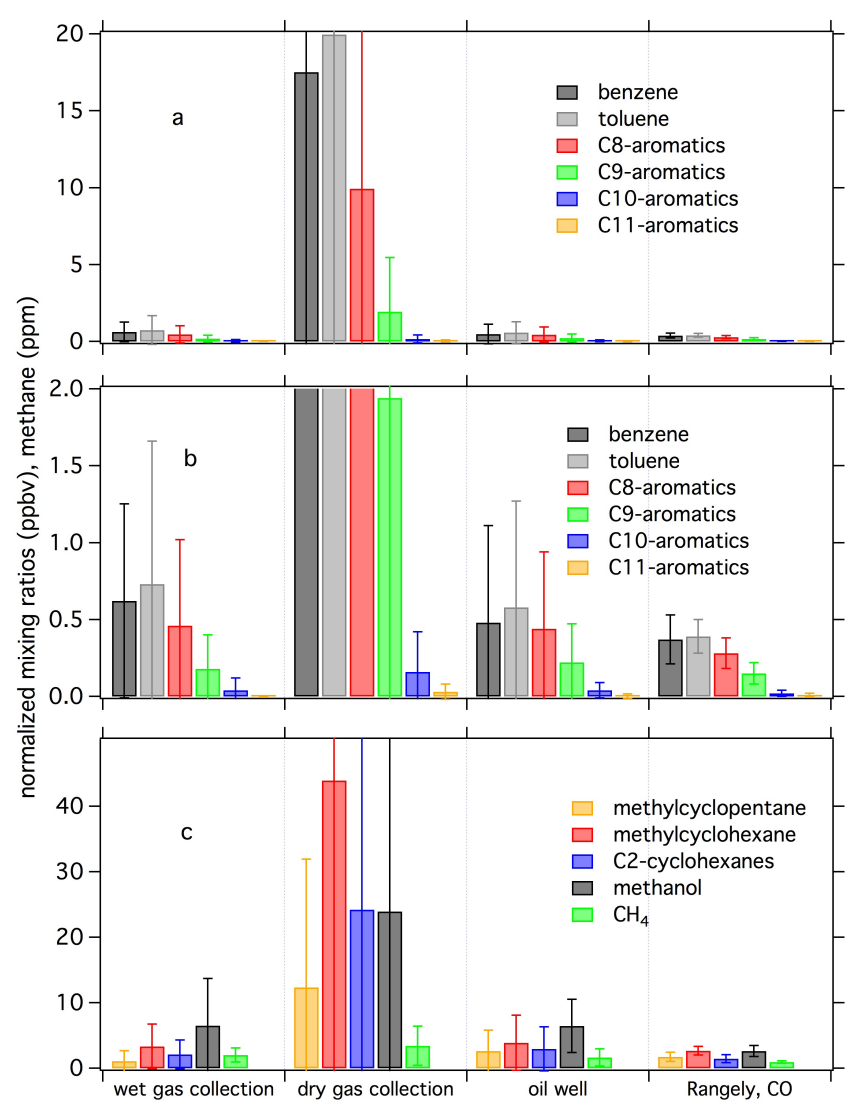

Figure 9. The average mixing ratio of various VOCs (aromatics, cycloalkanes, methanol and methane) close to emission sources in the Uintah basin are averaged for each category of point sources. The error bars indicate the standard deviation. All average mixing ratios next to the emission sources are normalized to an average $2 \mathrm{~m} \mathrm{~s}^{-1}$ wind speed.

this equipment at the well site, but have the dehydration and therefore the associated emissions at centralized facilities. Furthermore, the investigated wells using dehydrators on site generally had higher condensate production rates, which usually also lead to higher emissions, and, as shown in Fig. 5, the emissions of the aromatic compounds mainly came from the condensate tanks. No clear correlations of the average mixing ratios next to gas well pads with well age or cumulative well production were found.

As a comparison, also shown in Figs. 7, 8 and 9 are average mixing ratios close to gas wells in Rangely, Colorado, which is another part of the Uintah-Piceance Basin and located in the northwest corner of Colorado. About 20 miles (ca. $32 \mathrm{~km}$ ) separate the gas field in Rangely from the Uintah Basin, but the oil and gas exploration has a very different character. The gas field is much drier (less hydrocarbon liquids and more gas) and the density of wells is higher, which results in very different practices for the natural gas extraction. In the Piceance Basin about the same amount of gas, but only a little more than a quarter of oil, is produced com-
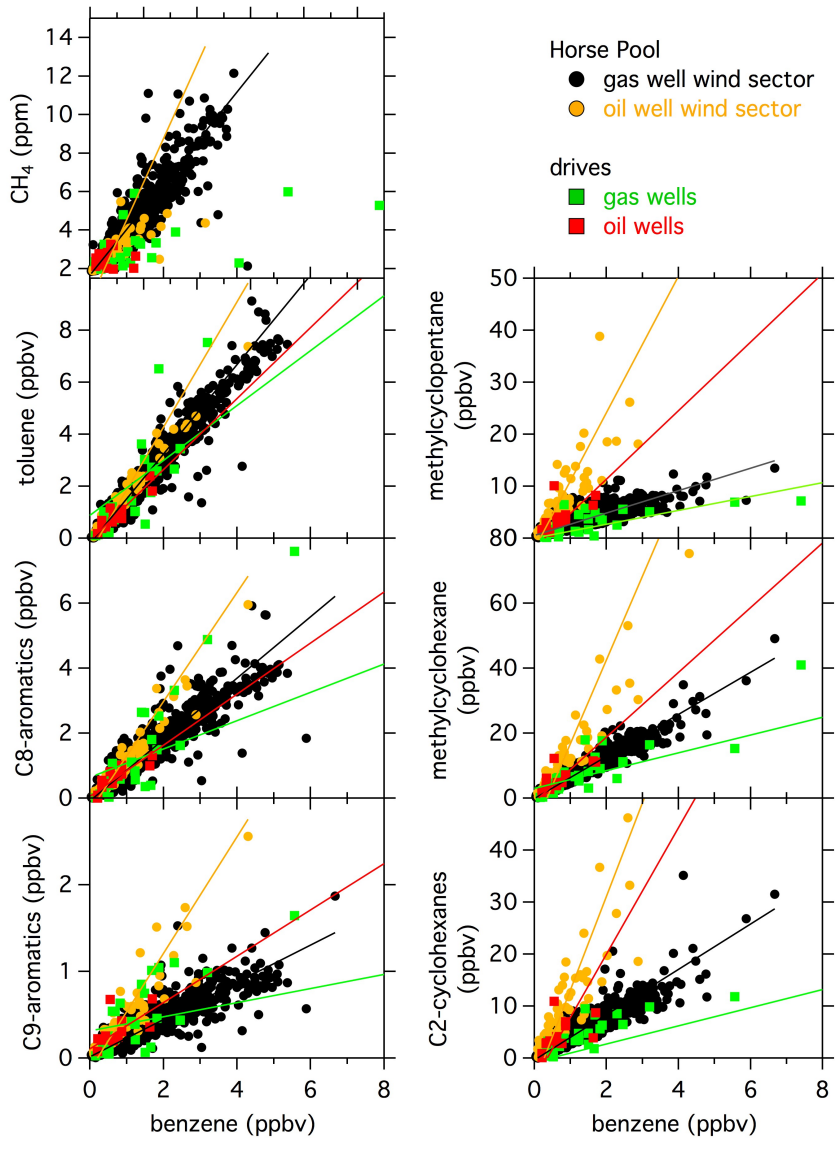

Figure 10. Scatter plots of various aromatics and cycloalkanes versus benzene for data from the Horse Pool ground site, separated into wind sectors that are dominated by either oil or gas wells, together with measurements from the mobile laboratory close to individual oil or gas well pads.

pared to the Uintah Basin. A photo of a typical gas well pad in Rangely, Colorado is also shown in Fig. 4b. The gas is transported with pipelines to a central facility in Rangely that is similar to the one at Uintah Basin, but in Rangely underground and in Uintah aboveground pipelines are used. Another difference is that in Rangely, electric power is available at most wells. As a result, few wellhead compressors, combustion generators or condensate tanks are used in this particular area, which are significant emitters of VOCs and $\mathrm{NO}_{\mathrm{x}}$ in the Uintah Basin. As a result, mixing ratios observed close to all investigated gas wells were still elevated from ambient but were generally lower than in the Uintah Basin.

Very large mixing ratios (e.g., ppmv levels of aromatics) were found downwind of a re-fractured well pad with flowback pond and a newly producing well. These are point sources that are less frequent than operating wells in the Uintah Basin. Emissions from these two sites were measured multiple times with the mobile laboratory.

The other point sources investigated, shown in Figs. 7 and 8 , included condensate and oil tank batteries, produced water 

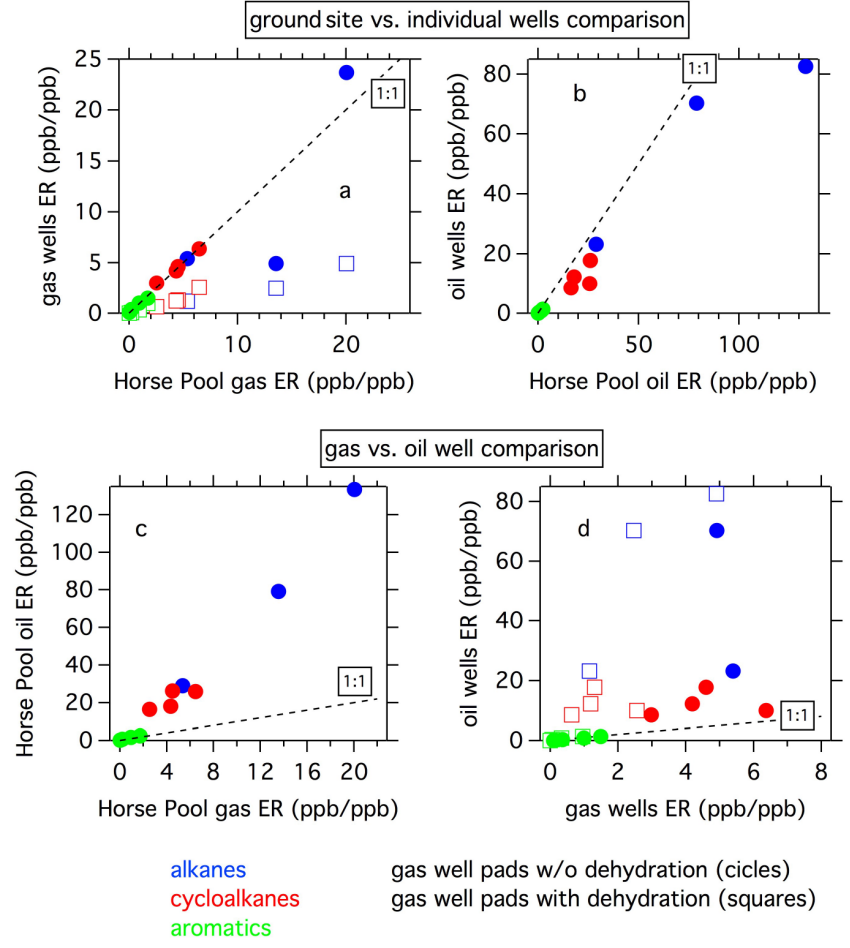

Figure 11. Enhancement ratios with benzene of aromatics (green), cycloalkanes (red) and masses measured with the PTR-MS that are indicative of alkanes in arbitrary units (blue). (a) Gas well pads without dehydration (circles) and gas well pads with dehydration (squares) compared to the gas well sector from the Horse Pool ground site data; (b) oil well pads compared to the oil well sector from the Horse Pool ground site data; (c) oil well sector compared to the gas well sector for the Horse Pool ground site data; and (d) oil well pads compared to gas well pads from the mobile laboratory data.

treatment plants, compressor stations, produced water evaporation ponds, and processing plants. We do not have enough measurements of the individual types of point sources to compare them in statistically meaningful ways to the oil or gas well pads, but mixing ratios close to those sources were generally in the same range as many of the gas well pads. Here it should be mentioned that the potentially largest sources (according to the WRAP inventory described below) of $\mathrm{VOC}$ and $\mathrm{NO}_{\mathrm{x}}$ in the Uintah Basin are the natural gas processing plants such as the Chapita Plant. These plants use stacks, and their main emissions cannot be reliably measured from the ground with the mobile laboratory.

Methanol is used as an anti-freeze and anti-coagulant, injected into pipelines and down the wellbore and, as a result, very high mixing ratios, often over $100 \mathrm{ppbv}$, were observed at many of the oil and gas well pads and at many of the other point sources. Methanol was especially high near the evaporation ponds, because methanol partitions out with the water in the separator. High mixing ratios of methanol were also observed at the Horse Pool ground site, often in very short-

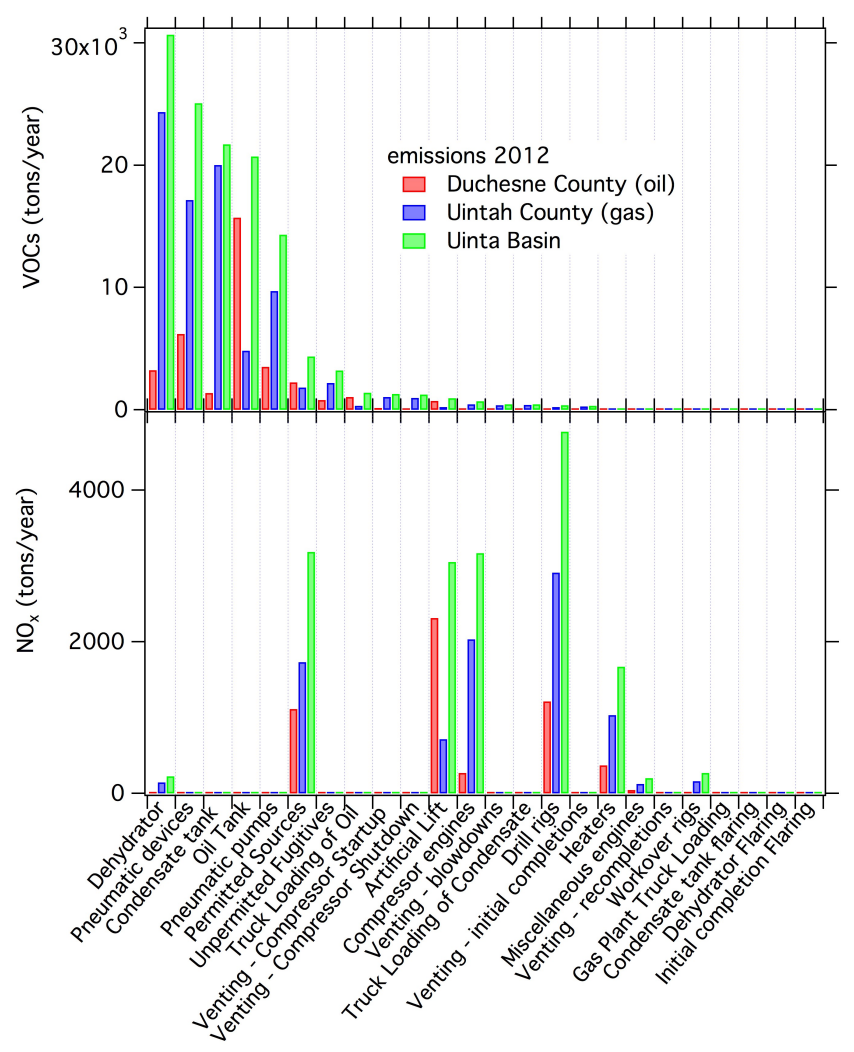

Figure 12. Total emissions of VOCs and $\mathrm{NO}_{\mathrm{x}}$ as estimated from the Uintah Basin emission inventory (WRAP inventory) by source category for Uintah and Duchesne counties and the Uintah Basin.

term spikes, as high as $1.1 \mathrm{ppmv}$ for the 1 min average. As can be seen in Figs. 5 and 6, methanol was emitted at the methanol tanks and the wellheads and was not well correlated with aromatics or methane close to the individual gas wells. Methanol was also one of the very few compounds that was not well correlated with the other hydrocarbons at Horse Pool (e.g. $R^{2}=0.18$ with benzene), due to the different processes emitting methanol at the well pads and the additional strong sources of methanol in the oil and gas region.

\subsection{VOC composition comparison of oil and gas well pad emissions}

Gas and oil wells are by far the most numerous point sources in the Uintah Basin and as such will be important emission sources of VOCs. Therefore we focus on the analysis of the VOC composition of gas and oil wells. Scatter plots of the measured VOCs versus benzene are used to compare the VOC composition emitted from oil and gas well pads to the ground site. The Horse Pool data are segregated into two classes based on their unique chemical composition. About $5 \%$ of the data exhibited a distinctly different chemical composition. For example, these samples were enhanced in $\mathrm{C}_{4}-$ $\mathrm{C}_{11} n$ alkanes relative to propane, but had a significantly 
lower ethane-to-propane ratio as measured by the GC-MS for the majority of the Horse Pool data. Wind sector analysis showed that these samples were almost exclusively from the northwest, where two nearby oil wells were located. The predominant wind direction at Horse Pool had a southern component where the vast majority of the gas wells in Uintah Basin are located. The $5 \mathrm{~min}$ averaged data from the two sectors (now referred to as oil and gas well sectors) are shown in Fig. 10, and are compared to the average mixing ratios close to oil and gas wells measured from the mobile laboratory (data from Figs. 7, 8 and 9). The left panel in Fig. 10 shows methane and the aromatics and the right panel the cycloalkanes. The Horse Pool data show good correlations for all compounds with benzene $\left(R^{2}>0.91\right)$, especially for the gas well sector. Ratios with benzene were used instead of the lightest compound methane, because most VOCs measured by PTRMS downwind of the gas and oil well pads did not correlate well enough with methane. The slopes of the larger aromatics and the cycloalkanes with benzene in the oil well sector are clearly different from the gas well sector, and the difference increases with the molecular weight of the compound. The mobile laboratory measurements from the individual wells show comparable slopes and differences between oil and gas wells, but the large well-to-well differences result in a larger variability. In Fig. 10 the linear fits for the four categories are shown together with the data.

In order to compare the emission profile of VOCs measured in the mobile laboratory downwind of oil and gas wells to the emission profiles observed at Horse Pool, we compare enhancement ratios with benzene shown in Fig. 11, where each data point represents one compound and is colored by compound class. Enhancement ratios are determined from the slopes of the linear fits (indicated for methylcyclopentane in Fig. 10), for cycloalkanes and aromatics as well as for the PTR-MS alkane masses with benzene. Figure 11a and $b$ compare the enhancement ratios for the individual gas wells with or without dehydrators and oil wells with the measurements from the Horse Pool ground site. In the surroundings of Horse Pool, wells without dehydrators dominate and their enhancement ratios are in good agreement with Horse Pool data. The wells with dehydrators do not agree as well with the Horse Pool data: the enhancement ratios with benzene, which is the lightest aromatic, are below the $1: 1$ line, which means that the composition of wells without dehydrators (alkanes, cycloalkanes and aromatics) is a lighter mixture of VOCs than the wells with dehydrators; however, wells with dehydrators had higher mixing ratios associated with them. The enhancement ratios for the oil wells and the oil well sector at Horse Pool agree well with each other, as shown in Fig. 11b.

Figure $11 \mathrm{c}$ and $\mathrm{d}$ compare the gas with oil well sectors at Horse Pool and the individual gas (with and without dehydrators) with oil well pads, respectively. The enhancement ratios with benzene for the oil well pads are clearly larger than the ones from the gas wells and the difference increases with the molecular weight of the compound. This shows that

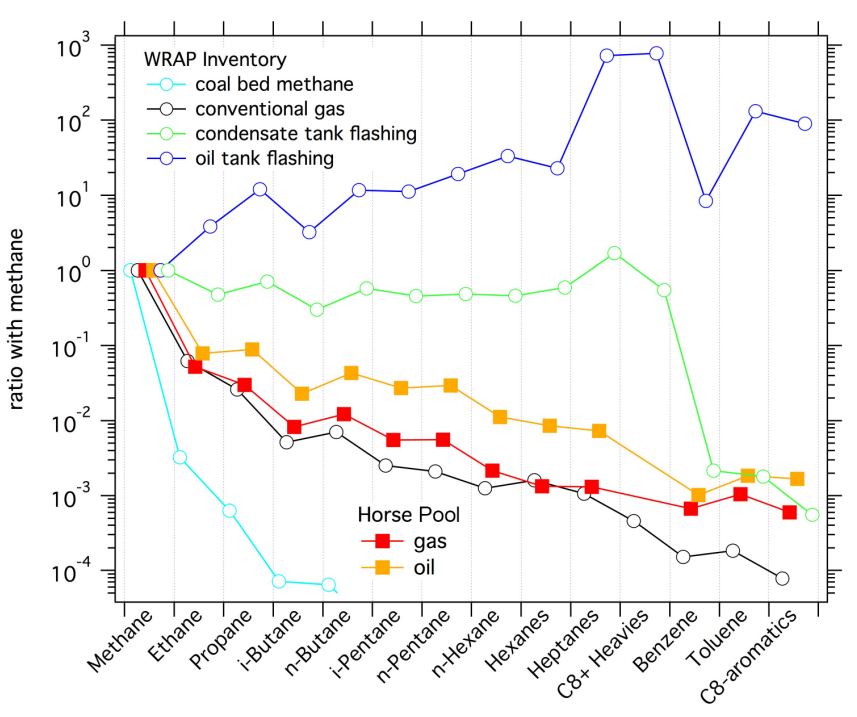

Figure 13. Emission ratios of VOCs with methane from the Horse Pool ground site compared to the WRAP inventory VOC emission composition of the conventional gas, oil and condensate tank flashing.

the VOC mixture emitted by oil well pads consists of heavier compounds compared to gas well pads, which is expected due to the heavier composition of the hydrocarbons extracted by oil well pads, as compared to gas well pads.

\subsection{VOC composition comparison with emission inventory}

The Uintah Basin emission inventory from the Western Regional Air Partnership (WRAP) provides an estimation of the criteria pollutant emissions for oil and gas exploration and production in the Uintah Basin for 2006 and projections for 2012 (available at http://www.wrapair.org/forums/ ogwg/PhaseIII_Inventory.html). The emissions calculated in the WRAP inventory are based on the well counts, production data and extensive operator survey data related to the identified oil and gas source categories. Figure 12 shows the VOC and $\mathrm{NO}_{\mathrm{x}}$ emissions as estimated by the WRAP inventory by source category for Uintah County (mainly gas wells), Duchesne County (mainly oil wells) and the entire Uintah Basin. In the inventory, about $89 \%$ of the VOC emissions are from dehydrators, condensate and oil tanks, pneumatic pumps and pneumatic devices, and about $78 \%$ of the $\mathrm{NO}_{\mathrm{x}}$ emissions are from drilling rigs, compressor engines, artificial lift engines and heaters. We did not systematically sample the largest $\mathrm{NO}_{\mathrm{x}}$ sources with the mobile laboratory and do not present an analysis of the NOx inventory here. In the WRAP inventory, fugitive emissions from oil and gas pipelines from wellheads to the main compressor stations are not included, which are potentially a large source category.

The VOC composition of each inventory source category is based on a composite gas and liquid analysis (provided by 
the different operators in the Uintah Basin) and calculations specific for each source category. The gas and liquid composition is calculated from an average of samples collected throughout the basin, but varies by location. From the main source categories, pneumatic devices and pumps emit raw gas and therefore the VOCs' composition is the same as the natural gas, whereas dehydrators and tank flashings emit less of the smaller hydrocarbons. In Fig. 13 the VOC composition used in the inventory for coal bed methane (CBM), conventional gas and oil, and condensate tank flashing is shown as ratios with methane. CBM is mainly emitted outside the study region, further south in the Uintah Basin in Carbon County, and is very light in VOC composition. The conventional gas shows the typical decrease of concentration with increasing molecular weight of the compound. The oil and condensate tank flashing emissions are depleted in smaller hydrocarbons, such that the $\mathrm{C} 7$ and heavier compounds make up the largest emissions from oil tanks.

Figure 11 showed that Horse Pool gas and oil well sectors compared closely to the individual gas and oil well pads, and therefore these data are used as a good proxy for individual wells. The VOC emission ratios with methane from Horse Pool are compared to the VOC composition used in the WRAP inventory in Fig. 13. The gas well pad measurements resemble most closely the conventional gas, but are heavier in composition, and the oil well pad emissions are even heavier, where the difference with the conventional gas is largest for the aromatic compounds. The measurements from the oil and gas wells and at Horse Pool will therefore be a mixture of conventional gas (from the pneumatic devices and pumps and other venting sources) with tank flashing and dehydrators, similar to what the WRAP inventory shows.

Measurements of the individual wells shown in Figs. 5 and 6 have demonstrated that VOCs are emitted with varying compositions from the different source categories. The measurements are qualitatively consistent with the WRAP inventory: (1) in the inventory, the dehydrator, the tank flashing and the pneumatic devices are major VOC emission sources from the gas and oil well pads, and we observe high mixing ratios of VOCs downwind of those sources (Figs. 5 and 6). (2) The inventory has emissions of heavier compounds from the oil and condensate tanks (Fig. 13), which we also see in the measurements (Figs. 5 and 6). (3) In the inventory, the wellhead, dehydrator and pneumatic devices emit raw natural gas as described above and the measurements show high methane mixing ratios downwind of these well pad parts (Figs. 5 and 6).

\section{Conclusions}

High mixing ratios of VOCs associated with emissions from oil and gas exploration and production operations (alkane, cycloalkanes, aromatics and methanol) were found in the Uintah Basin in winter 2012 at a ground site and using a mobile laboratory. Individual oil and gas well pads were investigated using the mobile laboratory, and it was found that the separator, dehydrator and pneumatic devices and pumps emit a light VOC mix similar to the natural gas composition, whereas the oil and condensate tanks emit heavier VOCs. High methanol concentrations were observed downwind of methanol tanks and condensate tanks. Other point sources, such as a flowback pond from a recently hydraulically refractured well and evaporation ponds, were also found to be large VOC emission sources. Looking at the measured VOC composition and the WRAP emission inventory it seems that the main emission sources in the Uintah Basin are individual well pads, such that the observed VOC composition is a mixture of raw natural gas with oil and condensate tank flashing.

The results presented here were some of the first measurements using fast-response VOC instruments to look at individual gas and oil well pads and other point sources associated with oil and natural gas production, but future measurements on a mobile laboratory are needed to determine emission rates in addition to ambient mixing ratios. For determining emission fluxes from well pads, techniques exist or are emerging, such as tracer releases and remote geospatial Gaussian methods or detailed measurements of individual equipment parts on the well pad, as shown by Allen et al. (2013), and should be used in future studies. Furthermore, more detailed fast-response VOC composition measurements are needed to better characterize the VOC composition of the individual source categories and identify the most important emission categories.

Acknowledgements. We thank Questar Energy Products, in particular Stephanie Tomkinson, for the Horse Pool site preparation and logistical support. We thank Nicole Downey for useful discussions. This work was supported in part by the Western Energy Alliance. This work was also supported by the NOAA Health of the Atmosphere Program and by the NOAA Climate Program Office - Atmospheric Composition and Climate Program. Felix Geiger acknowledges a grant from HGF Graduate School for Climate and Environment.

Edited by: J. Collett

\section{References}

Allen, D. T., Torres, V. M., Thomas, J., Sullivan, D. W., Harrison, M., Hendler, A., Herndon, S. C., Kolb, C. E., Fraser, M. P., Hill, A. D., Lamb, B. K., Miskimins, J., Sawyer, R. F., and Seinfeld, J. H.: Measurements of methane emissions at natural gas production sites in the United States, Proc. Natl. Acad. Sci. USA, 110, 17768-17773, 2013.

de Gouw, J. A. and Warneke, C.: Measurements of volatile organic compounds in the earths atmosphere using proton-transferreaction mass spectrometry, Mass Spectrom. Rev., 26, 223-257, 2007.

Edwards, P. M., Young, C. J., Aikin, K., deGouw, J., Dubé, W. P., Geiger, F., Gilman, J., Helmig, D., Holloway, J. S., Kercher, 
J., Lerner, B., Martin, R., McLaren, R., Parrish, D. D., Peischl, J., Roberts, J. M., Ryerson, T. B., Thornton, J., Warneke, C., Williams, E. J., and Brown, S. S.: Ozone photochemistry in an oil and natural gas extraction region during winter: simulations of a snow-free season in the Uintah Basin, Utah, Atmos. Chem. Phys., 13, 8955-8971, doi:10.5194/acp-13-8955-2013, 2013.

Francis, G. J., Wilson, P. F., Milligan, D. B., Langford, V. S., and McEwan, M. T.: GeoVOC: A SIFT-MS method for the analysis of small linear hydrocarbons of relevance to oil exploration, Int. J. Mass Spectr., 268, 38-46, 2007.

Fuchs, H., Dube, W. P., Lerner, B. M., Wagner, N. L., Williams, E. J., and Brown, S. S.: A Sensitive and Versatile Detector for Atmospheric NO2 and NOx Based on Blue Diode Laser Cavity Ring-Down Spectroscopy, Environ. Sci. Technol., 43, 78317836, 2009.

Gilman, J. B., Burkhart, J. F., Lerner, B. M., Williams, E. J., Kuster, W. C., Goldan, P. D., Murphy, P. C., Warneke, C., Fowler, C., Montzka, S. A., Miller, B. R., Miller, L., Oltmans, S. J., Ryerson, T. B., Cooper, O. R., Stohl, A., and de Gouw, J. A.: Ozone variability and halogen oxidation within the Arctic and sub-Arctic springtime boundary layer, Atmos. Chem. Phys., 10, 10223-10236, doi:10.5194/acp-10-10223-2010, 2010.

Gilman, J. B., Lerner, B. M., Kuster, W. C., and de Gouw, J. A.: Source Signature of Volatile Organic Compounds from Oil and Natural Gas Operations in Northeastern Colorado, Environ. Sci. Technol., 47, 1297-1305, 2013.

Howarth, R. W., Santoro, R., and Ingraffea, A.: Methane and the greenhouse-gas footprint of natural gas from shale formations, Clim. Change, 106, 679-690, 2011.

Karion, A., Sweeney, C., Petron, G., Frost, G., Hardesty, R. M., Kofler, J., Miller, B. R., Newberger, T., Wolter, S., Banta, R., Brewer, A., Dlugokencky, E., Lang, P., Montzka, S. A., Schnell, R., Tans, P., Trainer, M., Zamora, R., and Conley, S.: Methane emissions estimate from airborne measurements over a western United States natural gas field, Geophys. Res. Lett., 40, 4393 4397, 2013.

Katzenstein, A. S., Doezema, L. A., Simpson, I. J., Blake, D. R., and Rowland, F. S.: Extensive regional atmospheric hydrocarbon pollution in the southwestern United States, Proc. Natl. Acad. Sci. USA, 100, 11975-11979, 2003.

Kemball-Cook, S., Bar-Ilan, A., Grant, J., Parker, L., Jung, J. G., Santamaria, W., Mathews, J., and Yarwood, G.: Ozone Impacts of Natural Gas Development in the Haynesville Shale, Environ. Sci. Technol., 44, 9357-9363, 2010.

Litovitz, A., Curtright, A., Abramzon, S., Burger, N., and Samaras, C.: Estimation of regional air-quality damages from Marcellus Shale natural gas extraction in Pennsylvania, Environ. Res. Lett., 8, 014017, doi:10.1088/1748-9326/8/1/014017, 2013.

McKenzie, L. M., Witter, R. Z., Newman, L. S., and Adgate, J. L.: Human health risk assessment of air emissions from development of unconventional natural gas resources, Sci. Total Environ., 424, 79-87, 2012.

Peischl, J., Ryerson, T. B., Holloway, J. S., Trainer, M., Andrews, A. E., Atlas, E. L., Blake, D. R., Daube, B. C., Dlugokencky, E. J., Fischer, M. L., Goldstein, A. H., Guha, A., Karl, T., Kofler, J., Kosciuch, E., Misztal, P. K., Perring, A. E., Pollack, I. B., Santoni, G. W., Schwarz, J. P., Spackman, J. R., Wofsy, S. C., and Parrish, D. D.: Airborne observations of methane emissions from rice cultivation in the Sacramento Valley of California, J. Geo- phys. Res.-Atmos., 117, D00V25, doi:10.1029/2012JD017994, 2012.

Petron, G., Frost, G., Miller, B. R., Hirsch, A. I., Montzka, S. A., Karion, A., Trainer, M., Sweeney, C., Andrews, A. E., Miller, L., Kofler, J., Bar-Ilan, A., Dlugokencky, E. J., Patrick, L., Moore, C. T., Ryerson, T. B., Siso, C., Kolodzey, W., Lang, P. M., Conway, T., Novelli, P., Masarie, K., Hall, B., Guenther, D., Kitzis, D., Miller, J., Welsh, D., Wolfe, D., Neff, W., and Tans, P.: Hydrocarbon emissions characterization in the Colorado Front Range: A pilot study, J. Geophys. Res.-Atmos., 117, D0430, doi:10.1029/2011JD016360, 2012.

Ryerson, T. B., Aikin, K. C., Angevine, W. M., Atlas, E. L., Blake, D. R., Brock, C. A., Fehsenfeld, F. C., Gao, R. S., de Gouw, J. A., Fahey, D. W., Holloway, J. S., Lack, D. A., Lueb, R. A., Meinardi, S., Middlebrook, A. M., Murphy, D. M., Neuman, J. A., Nowak, J. B., Parrish, D. D., Peischl, J., Perring, A. E., Pollack, I. B., Ravishankara, A. R., Roberts, J. M., Schwarz, J. P., Spackman, J. R., Stark, H., Warneke, C., and Watts, L. A.: Atmospheric emissions from the Deepwater Horizon spill constrain air-water partitioning, hydrocarbon fate, and leak rate, Geophys. Res. Lett., 38, L07803, doi:10.1029/2011GL046726, 2011.

Schnell, R. C., Oltmans, S. J., Neely, R. R., Endres, M. S., Molenar, J. V., and White, A. B.: Rapid photochemical production of ozone at high concentrations in a rural site during winter, Nat. Geosci., 2, 120-122, 2009.

Spanel, P. and Smith, D.: Selected ion flow tube studies of the reactions of $\mathrm{H} 3 \mathrm{O}+\mathrm{NO}+$, and $\mathrm{O}_{2}+$ with several aromatic and aliphatic hydrocarbons, Int. J. Mass Spectr., 181, 1-10, 1998.

Swarthout, R. F., Russo, R. S., Zhou, Y., Hart, A. H., and Sive, B. C.: Volatile organic compound distributions during the NACHTT campaign at the Boulder Atmospheric Observatory: Influence of urban and natural gas sources, J. Geophys. Res.-Atmos., 118, 10614-10637, 2013.

US Energy Information Administration: http://www.eia.gov/ naturalgas/, 2014.

Utah Oil and Gas: http://oilgas.ogm.utah.gov/Statistics/Statistics. cfm, 2014.

Veres, P., Gilman, J. B., Roberts, J. M., Kuster, W. C., Warneke, C., Burling, I. R., and de Gouw, J.: Development and validation of a portable gas phase standard generation and calibration system for volatile organic compounds, Atmos. Measurem. Techn., 3, 683-691, 2010.

Warneke, C., Kuczynski, J., Hansel, A., Jordan, A., Vogel, W., and Lindinger, W.: Proton transfer reaction mass spectrometry (PTRMS): Propanol in human breath, Int. J. Mass Spectr. Ion Proc., 154, 61-70, 1996

Warneke, C., De Gouw, J. A., Kuster, W. C., Goldan, P. D., and Fall, R.: Validation of atmospheric VOC measurements by proton-transfer-reaction mass spectrometry using a gaschromatographic preseparation method, Environ. Sci. Technol., 37, 2494-2501, 2003.

Yuan, B., Warneke, C., Shao, M., and de Gouw, J. A.: Interpretation of volatile organic compound measurements by proton-transferreaction mass spectrometry over the deepwater horizon oil spill, Int. J. Mass Spectr., 358, 43-48, 2014. 